\title{
Anomalías en el Desarrollo y Formación Dental: Odontodisplasia
}

\author{
Development Abnormalities and Dental Training: Odontodysplasia
}

\author{
Diego Mauricio Ceballos O.; Gabriel E. Espinal* \& Mónica Jones ${ }^{\star \star *}$
}

\begin{abstract}
CEBALLOS, O. D. M.; ESPINAL, G. E. \& JONES, M. Anomalías en el desarrollo y formación dental: odontodisplasia. Int. J. Odontostomat., 9(1):129-136, 2015.

RESUMEN: El papel que desempeñan las alteraciones genéticas en el desarrollo dental es fundamental. Se ha descubierto que si no existe una correcta expresión del gen o se da una mutación de este, el individuo podría presentar ausencias o malformaciones de estructuras de la boca. Por esta razón se describe la forma en que se da el desarrollo de las estructuras dentales, teniendo en cuenta cómo las interacciones genética y ambiental influyen en su correcto desarrollo. Entre los genes involucrados se encuentran el PAX9 y el MSX1, que según recientes investigaciones son los implicados en las ausencias congénitas de estructuras dentarias o sus posibles alteraciones, teniendo en cuenta que la delación de estos genes o su mutación son factores hereditarios. Los genes odontogénicos PAX9 y MSX1, son genes homeóticos (homebox) que codifican para factores de transcripción y son responsables, durante la odontogénesis, de la expresión de genes asociados con la regulación espacial y temporal dentro del primer arco braquial. En determinado momento de la organogénesis pueden darse fallas en la expresión de los factores necesarios para la formación y buen desarrollo dental, causando anomalías como la Odontodisplasia Regional (OR), también denominada diente fantasma o detención localizada del desarrollo dental, la cual es una anomalía estructural del desarrollo, compleja y rara; parece ser el resultado de una o más mutaciones puntuales en el cromosoma 4 y 14 . Se reportan dos casos donde se describen las características clínicas, radiográficas, y el seguimiento clínico.
\end{abstract}

PALABRAS CLAVE: odontogénesis, morfogénesis, agenesias, odontodisplasia regional.

\section{INTRODUCCIÓN}

La dentición de los mamíferos es un sistema segmentado, constituido por una serie de elementos homólogos, de estructuras similares pero diferentes en forma y tamaño. En este tipo de sistema, alguna de las unidades puede estar ausente por falta de desarrollo, llevando a agenesias (Kolenc Fusé, 2004). En general se describen tres grandes etapas en la organogénesis: a) Iniciación, en la cual un conjunto de células reciben e interpretan la información posicional para iniciar la formación de un órgano en el lugar y momento correctos; b) Morfogénesis, durante la cual las células construyen el rudimento del órgano, y c) Diferenciación, en la que las células forman las estructuras específicas del órgano (Kolenc Fusé). En cuanto al entendimiento del control genético en la organogénesis dental, se conoce recientemente la identificación de genes, los homeobox, que son secuencias de ADN que están implicados en la regulación de la morfogénesis de los animales, cuyas mutaciones causan hipodoncia: msx1 para la forma autosómica dominante en el cromosoma 4, pax 9 asociada a oligodoncia y el gen para la displasia ectodérmica anhidrótica (EDA) en la forma ligada a $X$ en el cromosoma 14; estos genes también pueden verse implicados en las malformaciones dentales (Mostowska et al., 2006). Los genes homeobox codifican factores de transcripción que inician cascadas de otros genes, como todos los necesarios para la construcción de un miembro o en este caso de un diente (Mostowska et al.).

\footnotetext{
* Especialista en Odontología Integral del Niño y Ortopedia Maxilar, Facultad de Odontología, Universidad de Antioquia, Medellín, Colombia.

"Especialista en Odontología Integral del Niño y Ortopedia Maxilar, Universidad de Antioquia, Medellín, Colombia.

"*tEspecialista en Odontología Integral del Adolescente y Ortodoncia, Universidad de Antioquia, Medellín, Colombia.
} 
El msx1 está situado en el cromosoma 4 y es un gen que contiene un homeodominio y constituye una gran familia de multigenes altamente desarrollados, regulados por factores de transcripción (Mostowska et al.). Los casos reportados donde una mutación de msx1 es responsable de una agenesia dental autosómica dominante son pocos, y en esos casos, la agenesia dental puede estar combinada con otros rasgos fenotípicos, como labio hendido, paladar hendido, o labio y paladar hendido (Schuffenhaver et al., 1999). Las mutaciones con pérdida de función permitirían a las células diferenciarse tempranamente y dejar de proliferar, con la consiguiente falla en la morfogénesis (Miletich \& Sharpe, 2003).

El pax9 está situado en el cromosoma 14 y pertenece a los genes de la familia pax; en los mamíferos tiene nueve miembros, que codifican para factores de transcripción, los cuales juegan un papel fundamental regulando el desarrollo dental temprano (Mostowska et al.). Las mutaciones implicarían pérdida de función y producirían el fenotipo por haploinsuficiencia (Miletich \& Sharpe). Se sabe que la deficiencia de este gen puede ocasionar defectos en el desarrollo del mesénquima del arco mandibular; este se ha encontrado en la región molar desde el día 10 hasta el 16 de la odontogénesis (Mostowska et al.). Cuando se da una inadecuada expresión de estos genes se producen estas alteraciones y dependiendo de ello se pueden dar las ausencias o malformaciones; en el segundo caso la formación dental continúa, pero de una manera inadecuada, causando defectos con diferentes formas de expresión como son los defectos de esmalte, de dentina, de esmalte-dentina, etc. (Radlanski, 2003). Entre estos defectos se encuentran anomalías como la Odontodisplasia Regional (OR), también denominada diente fantasma o detención localizada del desarrollo dental, la cual es una anomalía estructural del desarrollo, compleja y rara (Metín et al., 1999). Los factores más comunes asociados a esta anomalía son, la evolución como factor general y la herencia como factor particular, parece ser el resultado de una o más mutaciones puntuales, que se da en un lugar específico del genoma, específicamente en el cromosoma 4 y 14 , los cuales pueden presentar mutaciones o ausencias (Seppala et al., 2006). Otros autores le han atribuido su etiología a los traumatismos locales o a otros factores asociados, entre los que se encuentran: 1) alteraciones vasculares, 2) mutaciones somáticas, 3) falla en la migración de las células de la cresta neural, 4) uso de medicamentos, 5) Infecciones virales y 6) trauma local. La OR también se ha visto asociada a otras patologías como: nevus vasculares (Marques et al., 1999), síndrome nuevo epidermoide (Klein et al., 2005), coloboma orbitario (Varela et al., 2008), atrofia hemifacial (Marques et al.) displasia ectodérmica e hidrocefalia (Zucchino \& González-Provinidell, 2001).

Esta anomalía afecta ambas denticiones: temporal y permanente. Existe una anormal aposición dentinaria, que a su vez está detenida precozmente (Thesleff, 2003; 2000). Se encuentran afectados todos los componentes histológicos del órgano dentario; radiográficamente el aspecto fantasma es típico: debido a la escasa radiopacidad del esmalte y dentina, raíces cortas y coronas dentarias que semejan conchas y aspecto dismórfico general (Mitsiadis \& Smith, 2006) y a la amplitud de la cavidad pulpar y canales radiculares dentarios. Su diagnóstico es fundamentalmente clínico y radiográfico (Klein et al.; Varela et al.; Marques et al.; Zucchino et al.) y tiene preferencia por el sexo femenino $(1,4: 1,0)$ y se presenta generalmente en el maxilar (2,5:1), en forma unilateral, afectando a los dientes anteriores (Klein et al.).

Estructuras dentarias temporales sanas pueden ser reemplazadas por dientes permanentes afectados (Seppala et al.). Esta condición se presenta en dientes contiguos de un cuadrante y generalmente no traspasa la línea mediana aunque los hallazgos histológicos fueran característicos. Las estructuras dentarias presentan superficies irregulares, con grietas y fisuras, son descoloridas o toman un color amarillo o amarillo-café. El esmalte es delgado y blando. Existe falla, retardo o erupción parcial de las estructuras dentarias. Es frecuente encontrar caries y abscesos gingivales (Thesleff, 1995; Metín et al.).

Radiográficamente las estructuras dentarias comprometidas muestran amplias cavidades pulpares, raíces dentarias cortas y ápices radiculares dentarios abiertos (O Carroll et al., 1991). El esmalte y la dentina se encuentran en capas delgadas y su radiopacidad es menor que en las estructuras sanas; se habla así de dientes fantasmas (Zucchino et al.).

Histológicamente se aprecia una cavidad pulpar con perlas calcificadas en su interior, así como también en los folículos dentarios de dientes no erupcionados. El esmalte se aprecia irregular, con zonas de aspecto normal adyacente a zonas hipoplásicas. Los cambios en la dentina son múltiples y van desde disminución en el grosor y número de túbulos dentarios, hasta fisuras y formación de dentina interglobular. Las áreas de dentina celular y amorfa se consideran patognomónicas de la OR (Zucchino et al. ). 
Se han descrito distintas modalidades de tratamiento, siendo algunas más conservadoras que otras. En general, si no existe infección, se realizan obturaciones adhesivas; en caso de infección, dependiendo de la severidad de las anomalías y la etapa de desarrollo radicular (Zagdwon et al., 2003). Se evalúa la posibilidad de realizar tratamiento endodontico (Ravassipour et al., 2005). En zonas edéntulas en pacientes niños se utilizan prótesis estéticas para restaurar la función, así como implantes de oseointegración cuando están indicados; en otros tratamientos se han trasplantado premolares desde zonas no afectadas a la zona de dientes afectados a los cuales se les realizó exodoncia, obteniendo resultados satisfactorios (Vitkov et al., 2006).

\section{REPORTE DE CASOS}

Caso 1. Paciente de sexo femenino que asiste a la facultad de odontología desde los siete años de edad, con buenas condiciones generales de salud, no presenta alteraciones sistémicas ni existen antecedentes familiares en relación con la aparición de la anomalía dental. En los antecedentes odontológicos sufrió trauma sobre incisivos centrales maxilares a los 3 años de edad que derivó en exodoncia del 51. Al momento de la primera consulta presentaba falta de erupción de centrales permanentes (Fig. 1A), y se observan radiográficamente anomalías en la dentición decidua 52, 53, 54, 55 (Fig. 1B) y en permanentes se encontraron afectados 11, 12,13, 14, 15 Y 16 (Fig. 1B). Luego de su erupción los dientes presentaron color marrón y malformaciones anatómicas, se encuentran acompañadas de inflamación gingival bucal y palatina. El resto de los dientes tienen aspecto y textura normal, sin caries ni gingivitis (Fig. 1C-D), se estableció el diagnóstico de Odontodisplasia Regional basado en los antecedentes clínicos y radiográficos, donde los dientes afectadas se aprecian con la imagen típica de diente fantasma, cavidades pulpares dentarias bulbosas y de límites indefinidos, conductos radiculares dentarios amplios (Fig. 1E-G). Evidenciando las dife-

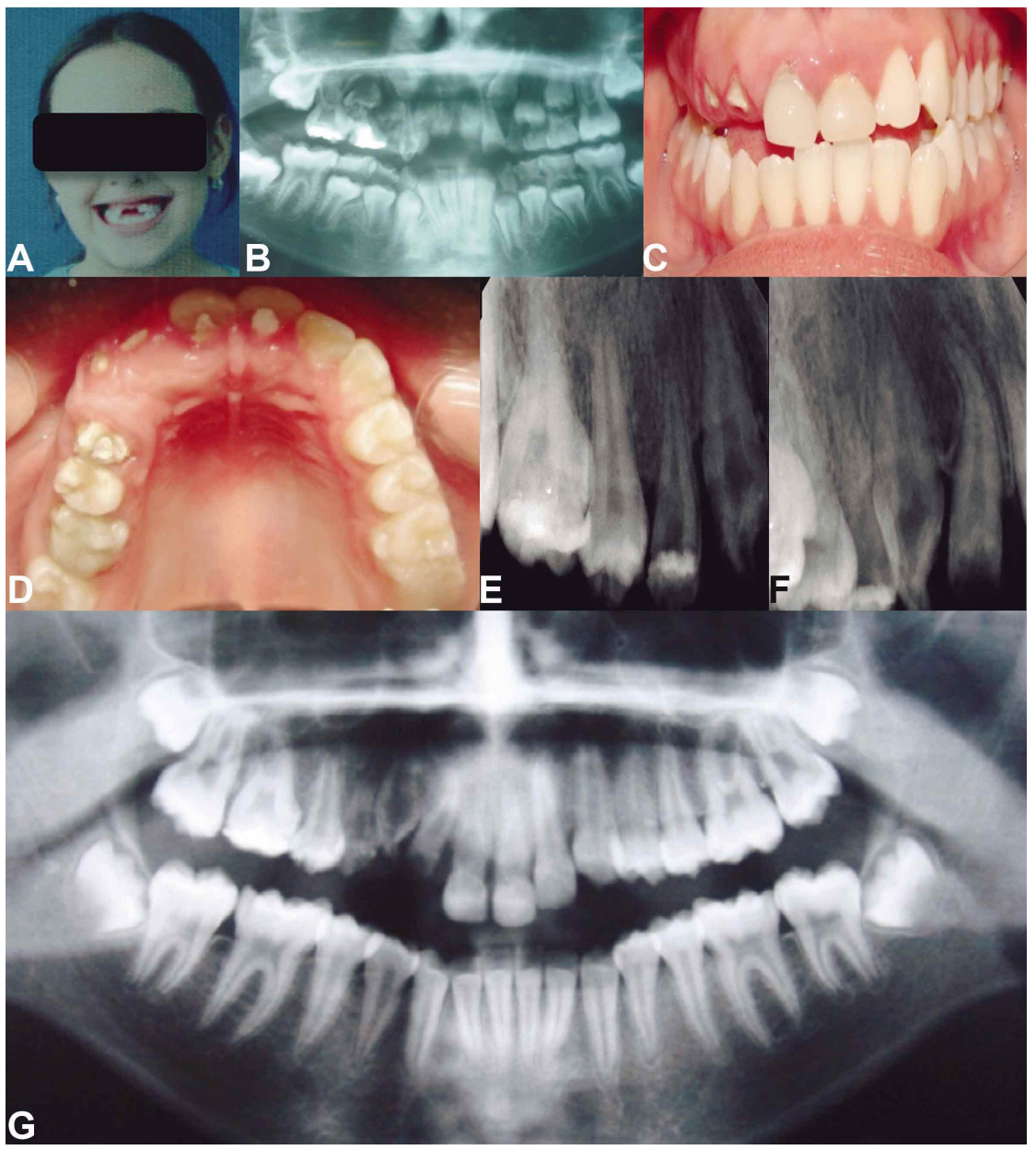

Fig. 1. Imágenes del caso referente a paciente de sexo femenino donde se observa falta de erupción de centrales permanentes (A), y anomalías en la dentición decidua y permanente en el maxilar (B). Luego de su erupción los dientes presentaron color marrón y malformaciones anatómicas (C-D). Se estableció el diagnóstico de Odontodisplasia Regional con la imagen radiográfica típica de diente fantasma, cavidades dentinarias y canales radiculares dentarios amplios (E-G). 


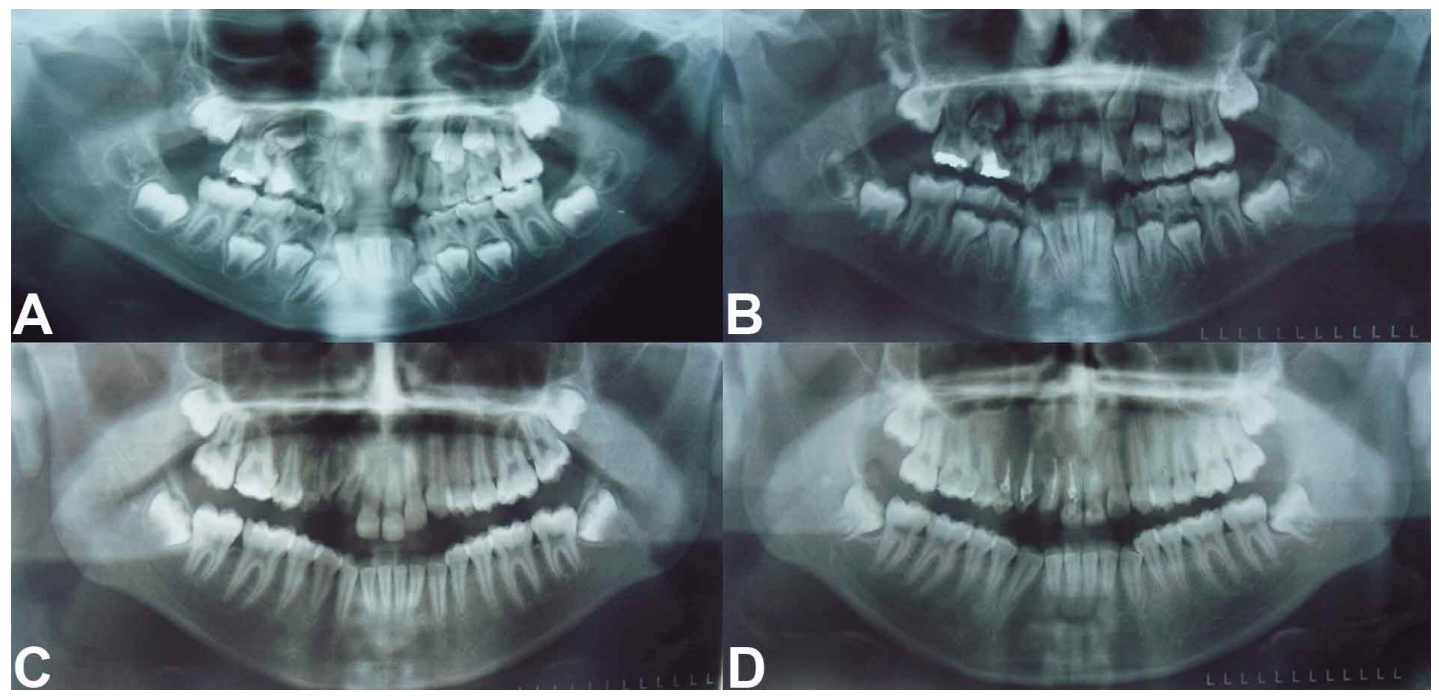

Fig. 2. Secuencia de radiografías panorámicas correspondientes a los años 2002 (A), 2003 (B), 2006 (C) y 2009 (D) referentes a paciente de sexo femenino.

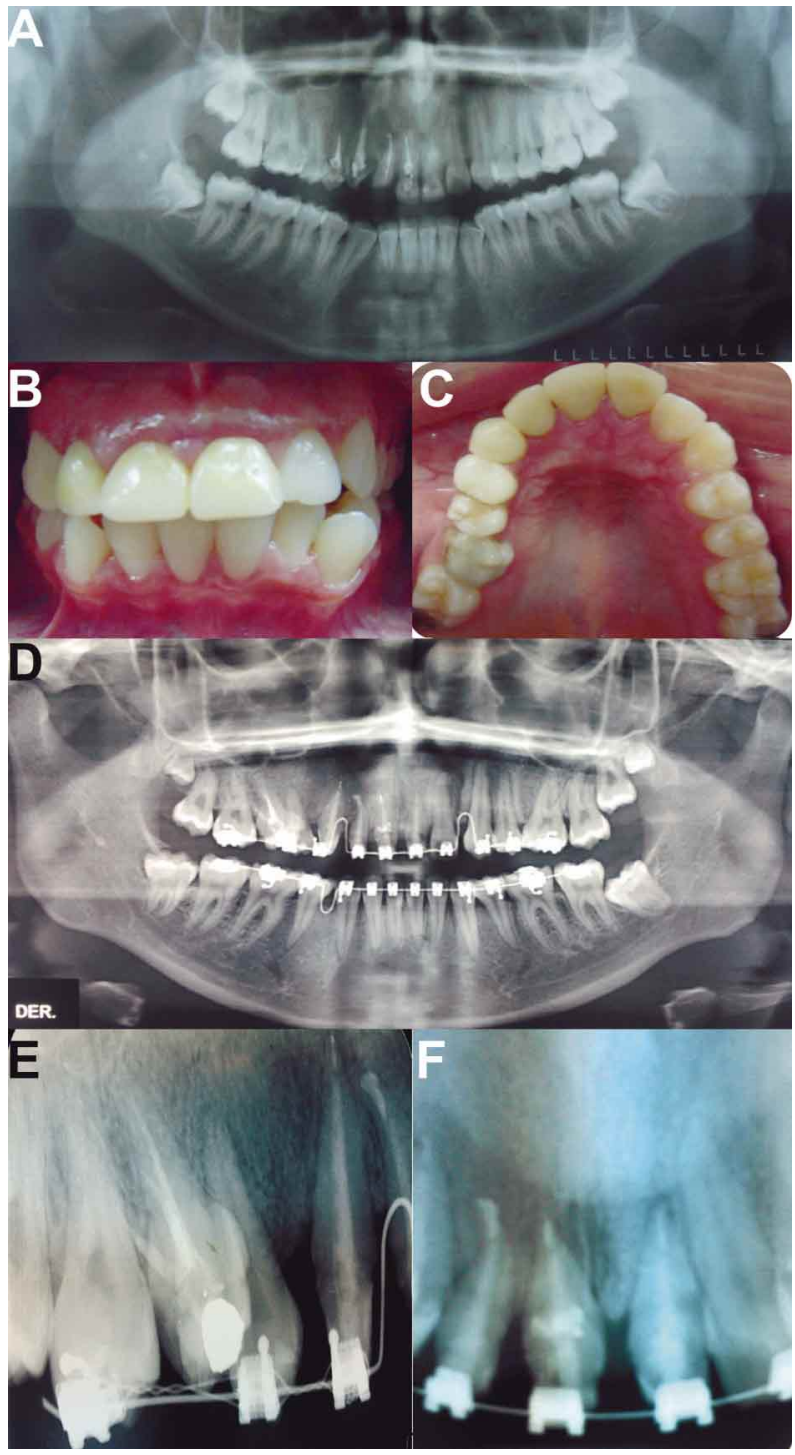

132 rencias entre los dientes afectados y la normal relación con su forma y densidad, lo cual se observa en la siguiente secuencia de radiografías panorámicas (Fig. 2A-D). Como tratamiento inicial se colocó aparatología funcional y luego una placa de Hawley con tornillo de línea mediana y dientes en acrílico desde el 12 al 15, para restaurar la función y la estética. Más adelante se restauraron 11 y 51 con resinas estéticas. Posteriormente se efectuaron endodoncias de 11, 12, 13 y 14 (Fig. 3A), y se rehabilitaron temporalmente dichos dientes (Fig. 3B-C). Actualmente le están terminando el tratamiento ortodóntico (Fig. 3DF) y luego se remitirá al posgrado de rehabilitación oral de la Facultad de Odontología de la Universidad de Antioquia para terminar su tratamiento.

Caso 2. Paciente de sexo masculino que asiste a la facultad de odontología de la Universidad de Antioquia desde el 2008, con buenas condiciones generales de salud, no presenta alteraciones sistémicas ni existen antecedentes familiares en relación con la aparición de la anomalía dental. Actualmente tiene 15 años de edad, radiográficamente los centrales maxilares se aprecian con la imagen típica de diente fantasma, cavidades pulpares dentarias bulbosas y de límites indefinidos, canales radiculares dentarios amplios (Fig. 4A), los laterales presenta raíces delgadas con muy poco soporte óseo (Fig. 4B-C), anteriores inferiores con desgastes incisales muy marcados (Fig. 4D), se observa ausencia congénita de caninos maxilares y

Fig. 3. Imagen que muestra tratamiento endodóntico de dientes anteriores maxilares (A), y su rehabilitación temporal (B-C). Sobre estos dientes se realiza tratamiento ortodóntico (D-F) en paciente de sexo femenino. 
mandibulares así como de primeros premolares maxilares y segundos molares maxilares y mandibulares (Fig. 4E-F); en la radiografía panorámica (Fig. 4G) los primeros molares presentan una solo raíz y taurodontismo al igual que los segundos premolares (Fig. $4 \mathrm{H}-\mathrm{I}$ ), con alteraciones de forma. Como tratamiento inicial luego de diagnosticar necrosis pulpar en 11 y 21 , se les realizó apexificación con hidróxido de calcio y obturación definitiva (Fig. 5A), después obturados se reconstruyeron con resina, al igual que los dientes laterales (Fig. 5B) y se colocan prótesis removibles estéticas maxilar y mandibular (Fig. 5C); actualmente el paciente sufrió fractura coronaria del 21 y necrosis pulpar del 22, por lo que se decide sumergir la raíz del 21 para preservar el hueso y realizar la exodoncia del 12 y 22, rehabilitando al paciente con dos nuevas prótesis estéticas, para restablecer también la función; también se reconstruyeron con resina los incisivos centrales y laterales de la mandíbula, (Fig. 5D-E). Se esperara que termine su crecimiento para su rehabilitación definitiva.

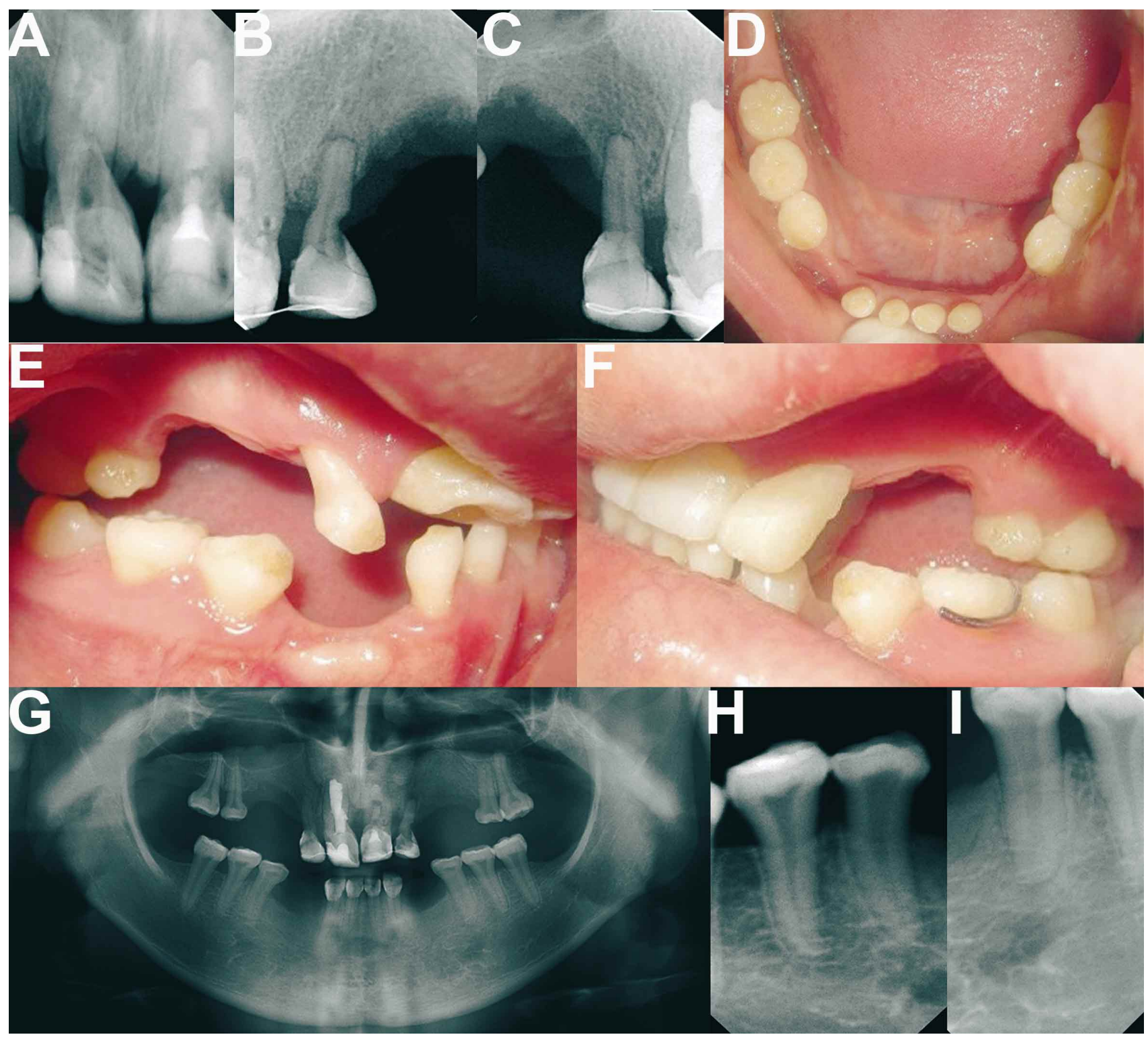

Fig. 4. Imágenes del caso referente al paciente de sexo masculino. Se observan radiográficamente incisivos centrales maxilares con imagen típica de diente fantasma (A), e incisivos laterales maxilares con raíces delgadas con poco soporte óseo (B-C). Los dientes anteriores mandibulares con desgastes incisales marcados (D). Se observa ausencia congénita de caninos maxilares (E-F) y mandibulares (D), así como de primeros premolares maxilares y segundos molares maxilares y mandibulares (E-F). Radiografía panorámica muestra a los primeros molares con una sola raíz y taurodontismo al igual que los segundos premolares (G-I). 


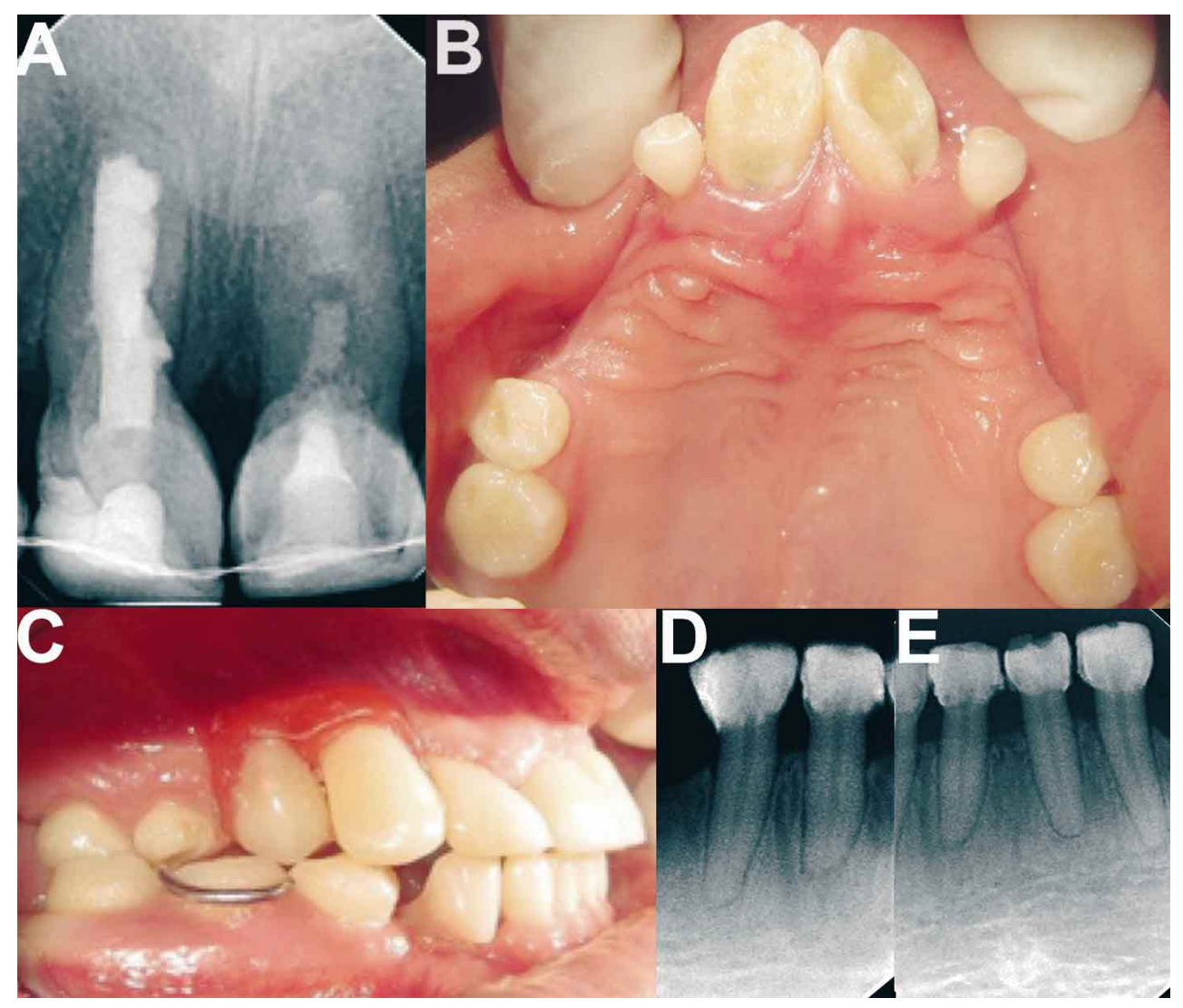

Fig. 5. Imagen que muestra tratamiento endodóntico de dientes anteriores maxilares (A), y su reconstrucción con resina $(B)$ en paciente de sexo masculino. Se colocan prótesis removibles estéticas maxilar y mandibular $(C)$; también se reconstruyeron con resina los incisivos centrales y laterales de la mandíbula (D-E).

\section{DISCUSIÓN}

Cuando se da una inadecuada expresión genética se producen alteraciones en la organogénesis y dependiendo de los genes afectados se pueden dar las ausencias o malformaciones, causando defectos como la OR, la cual algunos autores la asocian a una o más mutaciones puntuales, pero otros autores le han atribuido su etiología a los traumatismos locales o a factores sistémicos, siendo una patología de baja prevalencia y que su origen no está aún bien establecido.

Como en los casos reportados, están afecta ambas denticiones, dadas las características clínicas y radiográficas, el diagnóstico es básicamente clínico, y no se pudieron asociar a ninguna patología, ni a antecedentes hereditarios o familiares; sería ideal un secuenciamiento genético para tratar de encontrar los genes afectados. A diferencia de otro reporte de ca- sos (Gerlach et al., 1998), en estos no mejoró en el tiempo la anatomía radicular dentaria, si no al contrario se presentaron necrosis pulpares y fue necesario realizar tratamientos endodónticos y en uno de los pacientes dada la gran amplitud radicular dentaria, el diente sufrió fractura coronal, por lo que fue necesario sumergir la raíz para la preservación ósea y futuros implantes. Una vez establecido el diagnóstico como en los dos casos reportados, el manejo de los pacientes se debe encaminar a el restablecimiento de la función, la estética y la preservación de los dientes afectados para su posterior restauración definitiva cuando los pacientes lleguen a la edad adulta. EI tipo de rehabilitación de estos pacientes, dependerá de la integridad de los dientes afectados, pero durante esta etapa del tratamiento se les mantendrá con prótesis estéticas y restauraciones temporales tal como se reporta en la literatura (Zucchino et al.). 
CEBALLOS, O. D. M.; ESPINAL, G. E. \& JONES, M. Development abnormalities and dental training: odontodysplasia. Int. J. Odontostomat., 9(1):129-136, 2015.

ABSTRACT: The role of genetic alterations in tooth development is essential. It has been discovered that if there is a correct expression of the gene or there is a mutation of this, the individual could present absence or malformations of structures of the oral cavity or other body parts. For this reason we describe how given the development of dental structures, taking into account how genetic and environmental interactions influence their proper development. Among the genes involved are in the PAX9 and MSX1, which according to recent research are involved in congenital absence of dental structures or alterations, considering that the denunciation of these genes or the mutation is inherited. The odontogenic PAX9 and MSX1 genes are homeotic genes (homebox) that encode for transcription factors and are responsible, during odontogenesis, the expression of genes associated with spatial and temporal regulation within the first brachial arch. At some point during organogenesis may be flaws in the expression of the factors necessary for the formation and tooth development, causing among other abnormalities Regional Odontodysplasia (RO), also called ghost tooth or detention tooth dental development located, which is a structural anomaly development complex and rare; seems to be the result of one or more point mutations in the chromosome 4 and 14. In this report we show two cases with odontodysplasia where there are clinical and radiographic features of two patients with this anomaly, one of them has been made up and treatment, and the other begins his analysis stage.

KEY WORDS: odontogenesis, morphogenesis, agenesis, regional odontodysplasia.

\section{REFERENCIAS BIBLIOGRÁFICAS}

Gerlach, R.; Jorge, J. Jr.; de Almeida, O. P.; Coletta, R. D. \& Zaia, A. A. Regional odontodysplasia. Report of two cases. Oral Surg. Oral Med. Oral Pathol. Oral Radiol. Endod., 85(3):308-13, 1998.

Klein, M. L.; Nieminen, P.; Lammi, L.; Niebuhr, E. \& Kreiborg, S. Novel mutation of the initiation codon of PAX9 causes oligodontia. J. Dent. Res., 84(1):43-7, 2005.

Kolenc Fusé, F. J. Agenesias dentarias: en busca de las alteraciones genéticas responsables de la falta de desarrollo. Med. Oral Patol. Oral Cir. Bucal, 9(5):385-95, 2004.

Marques, A. C.; Castro, W. H. \& do Carmo, M. A. Regional odontodysplasia: an unusual case with a conservative approach. Br. Dent. J., 186(10):522-4, 1999.

Metin, M.; Ücok, C.; Keskin, A. \& Çizmeci, F. Regional odontodisplasia presenting as a soft tissue swelling. Tr. J. Med. Sci., 29:715-7, 1999.

Miletich, I. \& Sharpe, P. T. Normal and abnormal dental development. Hum. Mol. Genet., 12(Spec. No. 1):R6973, 2003.

Mitsiadis, T. A. \& Smith, M. M. How do genes make teeth to order through development? J. Exp. Zool. B Mol. Dev. Evol., 306(3):177-82, 2006.

Mostowska, A.; Biedziak, B. \& Trzeciak, W. A novel mutation in PAX9 causes familial form of molar oligodontia. Eur. J. Hum. Genet., 14(2):173-9, 2006.
O Carroll, M. K.; Duncan, W. K. \& Perkins, T. M. Dentin dysplasia: review of the literature and a proposed subclassification based on radiographic findings. Oral Surg. Oral Med. Oral Pathol., 72(1):119-25, 1991.

Radlanski, R. J. Development of the dentition: four-dimensional visualization and open questions concerning the morphogenesis of tooth form and occlusion. Orthod. Craniofac. Res., 6(Suppl. 1):82-8, 2003.

Ravassipour, D. B.; Powell, C. M.; Phillips, C. L.; Hart, P. S.; Hart, T. C.; Boyd, C. \& Wright, J. T. Variation in dental and skeletal open bite malocclusion in humans with amelogenesis imperfecta. Arch. Oral Biol., 50(7):611-23, 2005.

Seppala, M.; Zoupa, M.; Onyekwelu, O. \& Cobourne, M. T. Tooth development: 1 . Generating teeth in the embryo. Dent. Update, 33(10):582-4, 586-8, 590-1, 2006.

Schuffenhauer, S.; Leifhert, H. J.; Lichtner, P.; Peters, H.; Murken, J. \& Emmerich, P. De novo deletion (14)(q11.2q13) including PAX9: clinical and molecular findings. J. Med. Genet., 36(3):233-6, 1999.

Thesleff, I. Homeobox genes and growth factors in regulation of craniofacial and tooth morphogenesis. Acta Odontol. Scand., 53(3):129-34, 1995.

Thesleff, I. Genetic basis of tooth development and dental defects. Acta Odontol. Scand., 58(5):191-4; 2000. 
CEBALLOS, O. D. M.; ESPINAL, G. E. \& JONES, M. Anomalías en el Desarrollo y Formación Dental: Odontodisplasia. Int. J. Odontostomat., 9(1):129-136, 2015.

Thesleff, I. Developmental biology and building a tooth. Quintessence Int., 34(8):613-20; 2003.

Varela, M.; Botella, J. M.; García-Camba, J. M. \& GarcíaHoyos, F. Amelogenesis imperfecta: revisión. Cient. Dent., 5(3):239-46; 2008.

Vitkov, L.; Hannig, M. \& Krautgartner, W. D. Restorative therapy of primary teeth severely affected by amelogenesis imperfecta. Quintessence Int., 37(3):219$24 ; 2006$.

Zagdwon, A. M.; Fayle, S. A. \& Pollard, M. A. A prospective clinical trial comparing preformed metal crowns and cast restorations for defective first permanent molars. Eur. J. Paediatr. Dent., 4(3):138-42; 2003.

Zucchino; G. \& González-Provinidell, S. Odontodisplasia regional: Caso clínico. Rev. Hosp. Clín. Univ. Chile, 12:282-7, 2001.
Dirección para Correspondencia:

Gabriel Emilio Espinal Botero

Facultad de Odontologia

Universidad de Antioquia

Medellín

COLOMBIA

Email: Gabriel.espinal@udea.edu.co

Recibido: 19-09-2014

Aceptado: 04-03-2015 